\title{
DAS NATUREZAS QUE SE MOVEM PELO AFETO NA POESIA DE SÓNIA SULTUANE
}

\author{
OF THE NATURES THAT MOVE BY AFFECTION IN THE POETRY OF SÓNIA SULTUANE
}

\section{RESUMO}

Sónia Sultuane é uma escritora e artista plástica que vem ocupando lugar de destaque na cena cultural de Moçambique. A coletânea de poemas No colo da Lua (2009) revela uma voz poética no feminino que se relaciona com a natureza na perspectiva sinalizada pelos estudos ecofeministas referentes ao endosso de um exercício humanístico de proteger o mundo e as mais diversas manifestações da natureza. Para fundamentar essa localização epistemológica, vamos nos ancorar nos posicionamentos de Angélica Soares (1999) sobre erotismo e ecologia, de Carmen Tindó Secco (2014) sobre as reflexões em torno de afeto e poesia, de Greta Gaard (2017) sobre os rumos do ecofeminismo e de Izabel Brandão (2003) sobre as fronteiras críticas do ecofeminismo e da literatura.

Palavras-chave: Ecofeminismo. Poesia. Afeto. Sónia Sultuane.

\section{ABSTRACT}

Sónia Sultuane is a writer and artist who has been occupying a prominent place in the cultural scene of Mozambique. The collection of poems No colo da Lua (2009) reveals a poetic voice in the feminine that relates to nature in the perspective signaled by ecofeminist studies regarding the endorsement of a humanistic exercise to protect the world and the most diverse manifestations of nature. To support this epistemological location, we will anchor in the positions of Angélica Soares (1999) on eroticism and ecology, by Carmen Tindó Secco (2014) on the reflections around affection and poetry, by Greta Gaard (2017) on the direction of ecofeminism, and by Izabel Brandão (2003) on the critical frontiers of ecofeminism and literature.

Key words: Ecofeminism. Poetry. Affection. Sónia Sultuane.

\section{Primeiras colocações}

É inegável que a escrita de autoria feminina possibilita reflexões polêmicas, as quais acompanham a atualização dos estudos literários da contemporaneidade. Os estudos feministas propõem uma revisão epistemológica em vários setores de conhecimento humanístico. Aqui, selecionamos as contribuições que se voltam para o ecofeminismo como uma epistemologia possível à análise de textos literários de

Sávio R. F. Freitas

Universidade Federal da Paraiba. Email: savioroberto1978@yahoo.com.br 
autoria feminina. Pensar a relação da ecologia com literatura é uma tentativa de mostrar que a arte literária também é uma forma de protestar em favor do meio ambiente:

Estas questões nos propiciam uma compreensão mais extensa do significado da palavra ecologia e, com isso, propõem uma ampliação dos questionamentos relativos ao campo de debates sobre práticas ecológicas, pois, com seu caráter multidisciplinar, a ecologia deixa de ser um "motivo" de preocupação de, apenas, um grupo específico de ambientalistas. Ela se torna objeto de investigação e interesse de cientistas, de filósofos, de professores, de escritores etc., incorpora uma abrangência na esfera da reflexão e do debate intelectual (Torres, 2009: 157, grifos do autor).

Como bem menciona Maximiliano Torres (2009: 157), a perspectiva multidisciplinar coloca a ecologia como uma preocupação não só de ambientalistas, mas também de intelectuais que veem nesse espaço de discussão uma forma de debate sobre as relações humanísticas com o mundo. $\mathrm{O}$ ecofeminismo permite uma discussão agregada ao estudo de textos literários de autoria feminina, principalmente por recuperar uma agenda de discussão que já estava sendo feita por mulheres:

Como os feminismos desenvolvidos por mulheres de cor, o ecológico não é nem da segunda, nem da terceira ondas do feminismo, mas está presente de várias formas desde o seu início, no século dezenove, através de trabalhos das jardineiras, botânicas, ilustradoras, defensoras dos direitos e bem-estar dos animais, mulheres que trabalhavam em campo, cientistas e escritoras (Gaard, 2017: 788-789).

Greta Gaard (2017: 788-789), fazendo uma revisão da história do feminismo, defende que muitas temáticas ficaram invisíveis no espaço de discussão feminista por causa dos feminismos defendidos por mulheres brancas e reforçados por uma crítica machista perigosamente omissa. O tema da ecologia, segundo a pesquisadora norte-americana, já vinha sendo desenvolvido por mulheres preocupadas com o direito e o bem-estar dos animais, mulheres que trabalhavam no campo. Realmente, as mulheres transgressoras que têm uma origem territorial rural e trazem para seu universo de reflexão uma relação de afeto com a natureza, de algum modo, reverberam aspectos sinalizadores de um aprimoramento espiritual que se desenvolve por meio de uma interação de equilíbrio com a natureza:

A criação e a divulgação, pela mulher, de uma poesia que radicalize os modos literários de vivenciar conjuntamente o prazer integram, portanto, a consciência ecológica, no seu sentido mais globalizante, visto que as imagens do corpo, em 
harmonia com a Natureza e livre para o gozo, contrapõem-se aos mecanismos repressores da subjetividade e consequentemente aos da sociabilidade (Soares, 1999: 58).

Concordamos com Angélica Soares (1999:58) quando a pesquisadora brasileira defende que a poesia aliada ao prazer harmonizado com a Natureza materializa uma consciência ecológica que ataca os mecanismos repressores da subjetividade e da sociabilidade. Quando nos apropriamos do referido pensamento para analisarmos a produção literária da escritora moçambicana Sónia Sultuane, percebemos que a referida poeta já sinaliza em poesia uma relação de diálogo possível com os posicionamentos críticos até aqui pontuados, principalmente os que dizem respeito à expressão da subjetividade, à consciência ambiental e à relação erótica de prazer e afeto estabelecida com a natureza e com o território. Esses aspectos colocam a escritora Sónia Sultuane em lugar de destaque na Literatura Moçambicana de Autoria Feminina. Acrescentamos ainda que a relação de afeto com a natureza e com o território nacional sinalizam uma erotização poética urgente:

Era preciso erotizar Moçambique, fazendo pulsarem os desejos silenciados por séculos de violência e autoritarismo. Contra a dura realidade moçambicana, sonambilizada por sofrimentos ininterruptos, irrompe uma poética voltada para os recônditos da alma humana, para o inconsciente mítico do povo, para a procura da liberdade espiritual (Secco, 2014: 68).

Corroboramos a opinião crítica da pesquisadora brasileira Carmen Tindó Secco (2014: 68) sobre a precisão de erotizar Moçambique a partir de uma poética voltada para a libertação da alma humana. Moçambique é um país africano que passou por uma colonização portuguesa, maculando-o com uma cultura eurocentrada, patriarcal e androcêntrica ao ponto de intensificar um machismo já existente nas tradições culturais. O tema da libertação é muito exercitado na poesia de Sónia Sultuane e a sensualidade na escrita faz instigar a produção de escritoras contemporâneas como Hirondina Joshua, Melita Matsinhe, Enia Lipanga, Deusa D’África, entre outras que fazem da poesia um espaço de reconhecimento territorial, de consciência política, de aprimoramento de prazeres e afetos metaforizados pelas relações com as forças da natureza.

Sónia Abdul Jabar Sultuane nasceu em Maputo no dia 4 de março de 1971. Viveu em Nacala Velha, província de Nampula, até os oito anos. Possui ensino médio completo, porém, não chegou a cursar o nível superior, sendo isso uma de suas futuras ambições. Hoje, Sultuane trabalha em um escritório de advogados em Maputo. A poeta possui seis livros publicados: Sonhos (2001), publicado pela Associação de Escritores Moçambicanos (AEMO) e prefaciado pelo renomado poeta moçambicano Eduardo White; Imaginar o Poetizado (2006), publicado pela Editora Ndjira e prefaciado pela ensaísta Ana Mafalda Leite, a qual pontua no referido prefácio os 
aspectos da voz feminina de No colo da Lua (2009), editado pela própria escritora, e Roda das Encarnações (2016), publicado pela Fundação Fernando Leite Couto, em Moçambique; e pela Editora Kapulana em 2017, no Brasil. Há livros dedicados ao público infantil: A lua de N’weti (2014) e Celeste, a boneca com olhos cor de esperança (2017). A produção artística de Sónia Sultuane está intimamente ligada ao projeto intitulado Walking Words, o qual envolve poesia, artes plásticas e fotografia. A escritora costuma publicar poemas inéditos através do Facebook e lê poemas em seu canal do YouTube. ${ }^{1}$

\section{No colo da Lua: as naturezas moventes na poesia de Sónia Sultuane}

Neste estudo, vamos dedicar especial atenção à coletânea de poesias No colo da Lua (2009). Essa coletânea já apresenta em seu título um convite que bem se articula com a proposta do ecofeminismo, no sentido de experimentação poética da gestação da palavra se fazer no feminino. A relação ecológica do fazer poético com a Lua vai permitir que a voz de Sónia Sultuane nos conceda experiências poéticas existenciais possíveis pela relação de afeto e prazer de reconhecimento do corpo feminino como um espaço natural de libertação em diversos aspectos:

Os afetos, entre outros, que atravessam a poesia moçambicana são a indignação contra a colonização e a escravatura, o desejo de libertação, a solidariedade, amizade, etc. A nossa própria história como nação fez brotar mais esses tipos de afetos, que se agudizaram, em determinando momento, com a resistência à colonização, a luta de liberdade nacional, momento em que a poesia jogou também um papel importante como um veículo de informação e emoções. Em relação a minha poesia, os sentimentos que elegeria seriam o amor, a paixão, a esperança, os afetos e desafetos em geral (Sultuane, 2014: 159).

Como bem afirma Sónia Sultuane (2014: 159), a poesia moçambicana é uma forma de reagir às imposições coloniais por meio dos afetos. O afeto é uma forma de reconhecimento e de libertação dos desafetos. Quando a escritora nos convida ao colo da Lua, fica sugerida a ideia de que o colo lunar é o espaço da ternura, do acalento, do carinho, da paixão, da segurança, do conforto, do mimo, da carícia, do abraço, da liberação de uma miscelânea de sentimentos. A lua vem trazer a imagem poética de uma maternidade que se fortalece pelo espaço da natureza. A lua representa essa natureza da proteção materna. Essa voz poética, por meio de uma consciência ecológica, intersecta afeto, subjetividade e reconhecimento territorial, dialogando

1 A escritora possui um site em que publica toda a sua arte. Para os interessados em obter mais informações sobre a artista é só acessar: www.soniasultuane.com 
com o que Angélica Soares (1999: 58) afirma sobre a criação de uma poesia em que a consciência ecológica sugere libertação e gozo.

\author{
No colo da Lua \\ Quero olhar o céu \\ e contemplar a sua sombra dançando \\ na cadência do meu coração, \\ mergulhar no seu infinito, \\ no reflexo do azul esverdeado profundo, \\ sentir o cheiro do mundo percorrer-me as entranhas, \\ falar às estrelas prateadas, \\ sentar-me no colo da Lua armando a imensidão do \\ universo, \\ saboreando cachos de uvas pretas adocicadas, \\ para poder entregar-me a todos os sabores exóticos, \\ cantando e suspirando pela vida. \\ (Sultuane, 2009: 23)
}

Esse poema homônimo é um metapoema em que o eu-poético se posiciona no feminino. As palavras colo e Lua funcionam como um acalento em que pousa a voz poética desse poema. O poema tem duas estrofes que se interligam pelo encadeamento sugerido pelo verbo Quero no início da primeira estrofe. O encadeamento do verbo querer se enumera nas ações transpostas pelo eu-poético: olhar, contemplar, sentir, sentar, percorrer, falar, armar, saborear, poder, entregar, cantar e suspirar. Um encadeamento paralelístico que vai formando um ciclo lunar que preenche a unidade poética do poema acima. A Lua deita a voz poética em seu colo, como podemos notar no quinto verso da segunda estrofe: sentar-me no colo da Lua armando / a imensidão do universo; e exerce uma função de Musa inspiradora e permissiva à catarse proposta pela voz poética, a qual encontra na Lua o motivo e a permissão para o diálogo com a natureza e com a própria existência.

Liberdade

Quero ser a areia que cobre apressada a corpo desnudo do universo

Quero assobiar aos pássaros

a música despida dos ventos

baloiçar no luar despreocupado

fugir das mãos das árvores pregadas na terra soprar meu nome escrito na areia quente do deserto voar abraçada nos dedos dos pássaros para bem longe sem deixar marcas ou arrependimentos.

(Sultuane, 2009: 13) 
Reforçando a temática da liberdade, o poema acima, por meio de verbos de ação, permite o corpo poético se misturar aos elementos da natureza. A liberdade física se amalgama com a liberdade da natureza, compondo uma sintonia rítmica que dança ao tom natural da palavra. A voz em primeira pessoa chama para si o corpo cosmogônico, a voz poética se metamorfoseia em areia e se espalha por todos os versos. O verbo querer, anaforicamente iniciando a primeira e a segunda estrofes, reproduz paralelamente movimento de liberdade: na primeira estrofe, a liberdade está representada pela pressa de cobrir carinhosamente a nudez natural do universo; na segunda estrofe, mais uma vez a nudez natural está convocada sutilmente pela música dos ventos e pelo assobio dos pássaros, ficando a sonoridade da imagem marcada pela coliteração aliterada dos sons /t/ e /d/, como se pela palavra poética o vento suave apresentasse a sua sensação à poesia. A percepção ecológica da voz poética continua seu passeio sinestésico na terceira estrofe, invocando a liberdade por meio da metáfora da árvore. As mãos da poesia fogem pelo balanço da lua e pelos dedos dos pássaros. A liberdade não deixa arrependimentos. A terra é espaço que germina a poesia, que prende a árvore possivelmente também representando a sacralização da existência terrena. Nesse poema, a natureza mostra sua força divina pela existência efêmera da palavra poética que nos faz sentir, espiritualmente, a força natural existente em nós mesmos.

\section{Manjares exóticos}

Saboreias no meu corpo o gosto do amor nos meus mamilos dou-te o gosto do morango carnudo, no meu ventre o gosto do abacaxi, nas minhas coxas, nessas, dou-te mangas verdes, vens buscar na minha boca o açúcar, para aprisionares e mordiscares a tua fruta, nesse banquete inesquecível.

(Sultuane, 2009: 17)

O poema acima continua o exercício sinestésico por meio dos sabores metaforizados pelo corpo. O título do poema já sinaliza uma unidade que se sustenta pelo sabor divinizado: o manjar. O manjar é um prato oferecido para as deusas que habitam tantas mitologias ancestrais, principalmente as deusas que dominam a beleza, o prazer, o amor e a sensualidade. É como se a voz poética fizesse de sua poesia uma oferenda para o sagrado invisível da natureza. Há uma sensualidade característica da poética de Sónia Sultuane em cada verso. As frutas vão construindo a imagem da oferenda: o corpo é o espaço do amor, os mamilos são morangos, o ventre é o abacaxi, as coxas são mangas verdes, a boca é o açúcar, compondo então uma oferenda denominada banquete inesquecível. Sabores, gastronomia, tempero, corpo, sensualidade misturam as sensações e delimitam um territorialização cromática moçambicana (o vermelho do morango, o amarelo do abacaxi e o verde da manga). 
O exotismo está na manifestação de uma voz no feminino que apresenta seu corpo pela natureza dos sabores das frutas que invocam o desejo, o prazer e a poesia.

Chuva

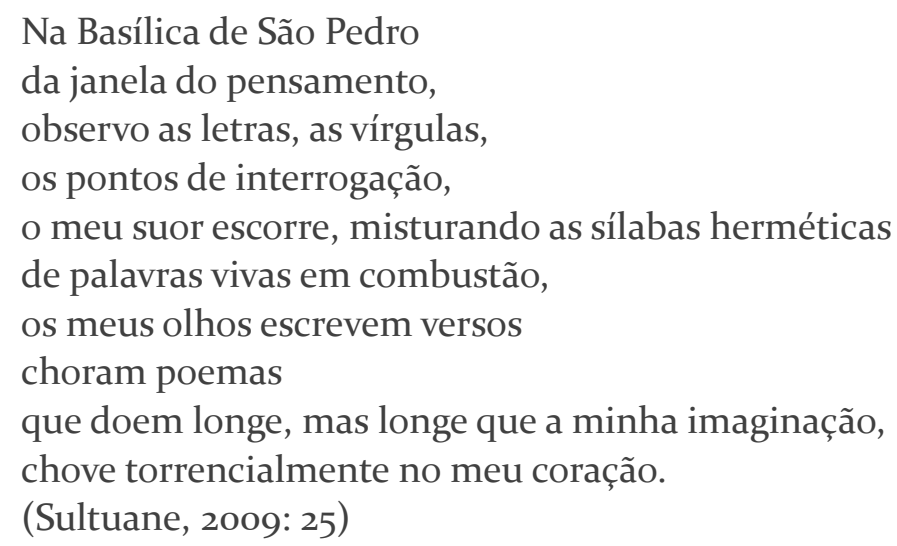

Mais uma vez, corpo e natureza se misturam na poesia de Sónia Sultuane. O sagrado se manifesta por meio de São Pedro, santo católico popularmente conhecimento por possuir a chave dos céus, controlar as chuvas e proteger os pescadores. O poema funciona como uma oração para o entendimento de si enquanto existência poética, e é composto com uma única estrofe, como se fosse um ato de invocação e apelo afetivo. A voz poética se coloca na janela da Basílica de São Pedro, local de onde o Papa manda mensagens consoladoras para o mundo. A chuva está representada no poema pela única estrofe que se desenvolve como uma queda de água em gotas metaforizadas pelas enumerações em sequência. Por meio da metapoesia, as palavras fazem a chuva intersectada com o corpo, como podemos observar nas seguintes passagens: o meu suor escorre, misturando as sílabas poéticas / das palavras vivas em combustão. A chuva intitula o calor das sensações poéticas. As batidas do coração presentes na sonorização permitida pelas aliterações em /p/ e /b/ amplificam a sonoridade do apelo da voz poética. A chuva mistura o sagrado e o profano em uma representação natural de um sentimento que se comprova naturalmente com poemas chorados. O corpo, novamente, é o vetor das sensações e manifestações da natureza. O contato da voz poética com a chuva representa o que Izabel Brandão (2003: 466) chama de escrita da natureza, quando os textos tratam de mimetizar o estado natural das coisas a partir de uma perspectiva poética. Sónia Sultuane inscreve a chuva no poema e as palavras se comportam como gostas de água que caem na folha em branco e formam uma poça de água, a qual está representada pela estrofe. 


\author{
Na margem do lago \\ No lago das orquídeas deitadas \\ banhei-me à conversa com as flores de lótus \\ baixinho, diziam-me que os cisnes \\ dormiam embalados com a música das folhas \\ trazidas pelas correntes do sul, \\ pediram que me banhasse tranquila \\ pois a brisa do sol, \\ embebedava-me com o meu perfume \\ a noz-moscada e flor-de-lis \\ pediram que me fundisse com as águas cristalinas \\ para que o meu cheiro não assustasse \\ na margem do lago as borboletas que nasciam. \\ (Sultuane, 2009: 29)
}

O poema acima apresenta uma manifestação do florescimento feminino que se põe à margem do lago. As flores funcionam como o domínio feminino sobre uma natureza que se fortalece pelo poder da água. O poema sugere uma associação do corpo em metamorfose em conversa com flores que metaforizam o desabrochar do feminino; as orquídeas, as flores de lótus e a flor de lis. Flores que sugerem a sensualidade da biologia feminina. A natureza mais uma vez se mostra cúmplice da imagem criada pela voz poética: as correntes do sul, as brisas do sol, as águas cristalinas hiperbolizam o empoderamento feminino marcado pelo nascimento das borboletas. $\mathrm{O}$ feminino que se apresenta nesse lago mais parece a personificação do sagrado feminino tão invocado pelas religiosidades que reconhecem o poder de ser mulher e ter condição de gerar assim como a natureza, que se nasce e morre, fazendo girar o ciclo da existência. A voz poética, mais uma vez, reforça o poder da natureza que se manifesta no feminino.

\section{Capulanas}

Amarro a vida aos nós do embalo do bebê coso a minha fé com as linhas da mão,

atiro ao mar as sete chaves do baú das capulanas já escolhidas pois ainda quero voar distante

guardo os ensinamentos da minha avó na alcofa esquecida da adolescência,

cubro-me com o manto da poesia para que meus sonhos de infância não sejam roubados.

(Sultuane, 2009: 71) 
O poema acima reverencia a ancestralidade materna. As capulanas marcam a territorialização da voz poética que rememora a vida seguindo a linearidade de existência. O poema é composto por quatro estrofes que funcionam como portais para o entendimento da existência da voz que se enuncia. Na primeira estrofe, sob o embalo do bebê, a capulana é amarrada pelas linhas da mão, linhas que representam o tempo e o destino escrito pela vida. A capulana também é um tecido utilizado pelas mulheres para carregar seus filhos amarrados nas costas. Volta aqui a questão do afeto representado pela identidade de um elemento que marca a cultura do povo moçambicano. Na segunda estrofe, as capulanas jogadas ao mar dentro do baú fechado a sete chaves marcam o rito de passagem da vida para a morte, a mudança de plano existencial, o plano físico e o plano espiritual. $O$ verbo voar funciona como uma intersecção entre o ato poético e o ato ritualístico. A terceira estrofe marca o momento da passagem da avó materna como um momento de ensinamento. Quando os mais velhos se vão, ficam as memórias didáticas de como sobrevir a dor da ausência. $\mathrm{Na}$ quarta estrofe, as capulanas funcionam como um manto poético que guarda os sonhos de uma infância que é convidada, no poema, pela memória ancestral. A natureza se agrega a essa manifestação poética sob a força de uma ancestralidade invocada pelo amor que sobrevive à vida e à morte. A poesia é um espaço natural para a imortalização de sentimentos.

Logo, diante das análises empreendidas, podemos comprovar que observar a relação das poéticas com a natureza possibilita confirmar que a literatura de autoria feminina, representada aqui neste estudo pela poesia de Sónia Sultuane, confirma que a crítica ecofeminista é uma epistemologia que, como afirma Izabel Brandão (2003: 408), renova novos conhecimentos dentro da literatura, deixando surgir análises sobre as relações da literatura com a natureza a partir de uma perspectiva crítica no sentido de fortalecimento de um consciência ecológica norteadora de uma organização do pensamento feminista sobre as relações de raça, classe e gênero. A natureza, por meio da crítica ecofeminista, passa a ser um espaço político de militância e preservação ambiental, espiritual e de humanitarismo.

\section{Últimas considerações}

Podemos concluir que, na poesia de Sónia Sultuane, ainda há muito o que se investigar. A consciência ecológica percebida na voz poética nos permite confirmar que o amor à natureza está associado ao afeto, à subjetividade e ao reconhecimento territorial. Os poemas aqui analisados mostram um poético comprometido com a movência da natureza em vários aspectos estéticos e ideológicos, a saber: o poder da maternidade, o valor da liberdade, o empoderamento do corpo feminino, a sensualidade da palavra, as manifestações do sagrado feminino e a reverência à ancestralidade materna. Muito ainda há que se observar sobre a natureza espiritual 
da poesia de Sónia Sultuane, pois esta é linha recorrente nas produções artísticas dessa multifacetada escritora moçambicana.

\section{Referências}

BRANDÃO, Izabel (2003). "Ecofeminismo e literatura: novas fronteiras críticas". In:___ _ MUZART, Zahidé. Refazendo nós: ensaios sobre mulher e literatura. Florianópolis: Ed. Mulheres.

GAARD, Greta (2017) . "Novos rumos para o ecofeminismo: em busca de uma ecocrítica mais feminista”. In: BRANDÃO, Izabel; CAVALCANTI, Ildney; COSTA, Claudia de Lima; LIMA, Ana Cecília Accioli. Traduções da cultura: prespectivas feministas (19702010). Florianóplis: EDUFAL; Editora da UFSC. p.788-789.

TORRES, Maximiliano. (2009). "O ecofeminismo: 'um termo novo para um saber antigo”. Revista Terceira Margem, Rio de Janeiro: n. 20: p. 157-75.

SECCO, Carmen Lúcia Tindó.(2014). Afeto e Poesia: Ensaios e Entrevista: Angola e Moçambique. Rio de Janeiro: Oficina Raquel.

SULTUANE, Sónia. (2001). Sonhos. Maputo: AEMO. (2006). Imaginar o poetizado. Maputo: Ndjira. . (2009). No colo da Lua. Maputo: s/e. . (2014). A Lua de N'weti. Santo Tirso: Editorial Novembro. . (2014). "Entrevista”. In: SECCO, Carmen Lúcia Tindó. Afeto e Poesia: Ensaios e Entrevista: Angola e Moçambique. Rio de Janeiro: Oficina Raquel. p.157-16o. . (2017). Roda das Encarnações. São Paulo: Kapulana. . (2017).Celeste, a boneca com olhos cor de esperança. Santo Tirso: Editorial Novembro.

Recebido em 30/05/2020.

Aceito em 21/o6/2020. 